\title{
Magda Jeanrenaud, Despre etica traducerii. Exerciții practice, Editura Universităţii „Alexandru Ioan Cuza”, Iași, 2017, 208 p.
}

\author{
Gabriela-Iuliana Morcov* \\ Doctoral School of Philological Studies, "Alexandru Ioan Cuza" University, Bd. Carol I 11, 700506 Iași, Romania
}

The recent work penned by Magda Jeanrenaud, published by the "Alexandru Ioan Cuza" University Press in Iaşi, joins the other studies of reference that the author has dedicated to translation critique and evaluation. The translating activity of Magda Jeanrenaud establishes a specific system of ideas and at the same time, it authorizes the exegete's assumed endeavour of contributing critically to the crystallization of a research field that still builds by trials its methods and instruments. The volume comprises a series of studies which - whereas elaborated to address independently certain particular matters of interest are now put together through several theoretical and methodological constants subordinated organically to the central topic of the book: the ethics of translation. The five chapters comprising the core of the work are framed by two other studies, highlighted here as an introduction to the volume and as an ending text, respectively.

The study designed to stand as a preface brings to attention two texts that - in different settings and on different paths - seem to proclaim the impossibility of translation, the perspective that has always provided a hint of drama to the translation phenomenon. We refer here to the well-known text of Walter Benjamin, Die Aufgabe des Übersetzers and to the preface penned by the linguists JeanPaul Vinay and Jean Darbelnet for the work Stylistique comparée du français et de l'anglais: méthode de traduction. Nonetheless, this volume-like other studies and theories written in the field of translation studies-illustrates that this verdict is relative, and the phrase "from the «impossibility » of translation to the critique of translation" within the title of this introductory section actually synthesizes the belief revealed by Magda Jeanrenaud. She posits, "Only the critique and evaluation of translations, doubled by an ethics of translators, may propose an alternative to the dramatic belief that translation is not possible" (p. 14). This is, indeed, one of the guiding ideas of the entire volume.

The "few reflections on the status of Romanian translation studies", which the author includes in the first chapter of the work, were generated by two seemingly contradictory opinions regarding the identity of Romanian translation studies. On one hand, the diagnostic formulated by Janos Kohn in the 1998 edition of the famous Encyclopedia of Translation Studies, according to which "translation theory remains closely connected with practice in Romania" (p. 17). On the other hand, more than a decade and a half later, the verdict issued by Georgiana Lungu Badea in a study where she argues that, in the context of international events and globalization trends, "the theoretical contributions brought by the Romanian researchers-translations and linguistsare numerous and varied" (p. 18). In an attempt to evaluate the extent to which the two opinions are grounded, Magda Jeanrenaud features in parallel three key moments within the evolution of translation studies thought in the Romanian space: the '60s, the ' 80 s and the translation studies at the threshold between centuries: 1995-2014. This approach from a diachronic perspective provides to the author the data necessary to reveal the way the dynamic of the reflections on translation studies in the Romanian space is determined by a broader historical and cultural framework. It also allows her to observe the way the definite detachment from tradition that defines the current stage of Romanian translation studies has led to the dilution of any existing native specificity. Whereas the first two periods have as element of continuity the interest for the practice of translation conjugated with caution regarding the role of linguistics on translation and the delimitation from theory, the current moment of Romanian translation studies

\footnotetext{
*Email address: gabriela_morcov@yahoo.com.
} 
tends, the author notices, towards a synchronization with the European reflection through the simple reprisal of the Occidental theories, without an interest to integrate them in the native culture. The author knows that the Romanian element belongs to a broader non-homogeneous setting, where the influence networks reflect the domination of the great cultures (diffused by the central languages) over the small cultures (diffused by the peripheral languages). She expresses-at the same time-the belief that translation thought can only be developed in close connection with the evolution of the language expressing it. Hence, Magda Jeanrenaud does not hesitate to expose the consequences entailed by the globalization trend of the Romanian researchenabled by the international academic circuit and by the events within the internal circuit-on the specifics of the current translation studies reflection in the Romanian space.

In the Romanian cultural space, the difficulty of translating concepts remains a current issue despite the entire historical background, which proves once again "the slow penetration of innovation in tradition" regarding the translation methods, as the author formulates a possible explanation (p. 69). This difficulty justly intensifies in the discourse of humanities, a discourse whose functional identity has never been very clear. It is not comprised, in the opinion of certain theoreticians, within binary categories (pragmatic text - literary text) or within those delimited through the trichotomy of functionalist inspiration, elaborated by Katharina Reiss based on the communicational scheme designed by Karl Bühler (informative texts - expressive texts appellative texts). In the study titled Despre traducerea conceptelor in discursul științtolor umane [On translating concepts in humanities discourse], the author identifies and illustrates several key elements entailing this difficulty. They include the need to translate both the rhetoric and the poetics of a text; the approach to terminological lexicon in conjunction with the general lexicon; the novelty status of specialized terms, often associated to subjectivities. By exposing a relevant theoretical framework and by using examples taken from the Romanian versions of reference works in the fields of linguistics, sociology and translation studies, the author examines the strategies used by translators. Her examination follows two axes: the translation of the concepts and the translating options meant to reconstruct the poetics of the text (in other words, the level of the word and the level of the syntax). This process allows the observation of certain recurring translation methods where the author identifies frequent deontological breaches that she subjects to a necessary analysis. Through this exegetic endeavour, we are invited to re-evaluate the guarantee that Romanian translations provide in terms of transposing certain fundamental concepts from the source language. Furthermore, in order to become persuaded that such awareness is necessary, it suffices to analyze the critical study that the author conducts regarding the translations of Saussure's Course in General Linguistics. By limiting the research to the transpositions of two examples within the Saussurian terminology, namely la masse parlante and le total, a relevant analysis for the way Romanian translations treat the conceptual lexicon of modern linguistics, the author demonstrates how the novelty of Saussure's view is "cancelled at the stroke of a pen". The author highlights, once again, the danger resulted from ignoring the deontological components in translational endeavour: "Hence, translation can kill, by demolishing, an entire symbolic capital in a target language and culture” (p.61).

The study exceeds the limits of the area of interest shown by translators and translation studies specialists and it proves to be relevant for any philologist and mostly for any specialist who wishes to develop their own research studies based on texts that they received through the filter of translators.

In a work where the author proposes to discuss the ethics of translation, it would have been unnatural to avoid a discussion of the classical translatable - untranslatable dispute, and the entire endeavour would have had less of an impact upon the reader who attempts to get to know and to define the phenomenon of translation. Titled Traducerea: intre ce se poate traduce și ce trebuie tradus [Translation: between what can be translated and what must be translated], the third study of the volume updates this debate, by examining carefully the English, French and Romanian translations of the wellknown essay by Walter Benjamin, Die Aufgabe des Übersetzers. More precisely, she examines the two citations included therein: a citation from Mallarmé and a citation from Pannwitz. The translatable untranslatable tension brings to light the translator's behaviour, often trapped between "the phantasm 
of untranslatable" and the "euphoria of unlimited translatability", and the investigation conducted by Magda Jeanrenaud underlines the points won and those lost by each version pursuant to the translation options. Whereas the perspective of untranslatability derives from the imperative of fidelity towards the author's intentionality, the exegete mentions the saving role of functionalist-inspired theories, which turned dominant function into a basic translating principle. Furthermore, the theoretical observations that the author introduces strategically throughout the study facilitate the understanding of the ways in which the fracture between fidelity and translation can be mitigated in the translation process.

The author's warning regarding the "euphoria of unlimited translatability" is even more substantiated in the subsequent study, titled Cum se traduce rusinea. Abordare traductologică [Translating 'shame'. A translational approach]; it is one of the most consistent "practical exercises" included in the volume, which also entails the instructive character of the project. Through the case study proposed, a comparative translation study of the work penned by Boris Cyrulnik, titled Mourir de dire. La honte (Editions Odile Jacob, Paris, 2010) and of its Romanian translation, titled Mai bine mor decît să spun. Ruşinea (traducere din limba franceză de Valentin Protopopescu, Editura Trei, col. „Psihologia pentru toți”, București, 2012), the author proposes to analyze the current working strategies and the translators' options in a context that seemingly still lacks a coherent and well-structured notional lexicon. The major challenge involved by the translation of Cyrulnik's book is precisely its functional identity, its situation "somehow halfway between a specialized treatise and an essay" (p. 113), thus involving an oscillation between the informative and the expressive nature. The theoretical background provided to the translator by the functionalist theories of translation and mostly by the skopos theory elaborated by Katharina Reiss must be approached in a skilful and professional manner. Indeed, in this context, any translation endeavour can be successful only insofar as the translator transposes integrally the cognitive contents, by avoiding ascribing an artificial character to semantic nuances, grammar or stylistics. The inventory of translational options is very detailed and it supports the assessment presented by the author in this part of the book. This inventory allow us to observe, along with the author, the way some of the most prominent downsides of the entire translation derive either from the translator's failure to construct a grid of specialized terms symmetrical to the one of the source text, or from avoiding to neologize the adjective ruşinos, or from the excessive freedom taken by the translator by distorting the register. In order to demonstrate the complexity of the process and the rigour of this type of labour, the author completes the analysis using comments referring to three belletristic texts, where she highlights the different logic of the translation of the word rusine in the texts with expressive dominance. This is also the context where Magda Jeanrenaud returns to the idea of a translator's limited freedom; when translating, they must transpose a text from a source language into a target language, by adjusting the translation techniques in close dependence on the type of text to translate and on the intention that generated the text.

The last study, Despre beneficiile comparatismului in critica traducerilor sau de ce trebuie retradusă opera lui Sigmund Freud in limba română [On the benefits of comparative study in translation critique or why the work of Sigmund Freud must be retranslated into Romanian], has a very transparent title concerning the stakes of the text. Thus, Magda Jeanrenaud discusses an insufficiently valorised lever, which the critique of translation may take into account in its mission of facing the difficulties that must be overcome if the ideal is represented by a successful translation: the comparative study. The core of the study is represented by the investigation applied by the author to the translation project of Freud's work into Romanian. She uses constantly the homologous endeavour within the French cultural space; hence, the reader has the possibility of comparing "two different histories of translating the same source text” (p. 147). Generally included in the category of texts with an informative dominant, Freud's work represents a type of text whose intentionality concerns precisely the terminological coherence. However, the Romanian edition often fails to achieve conceptual unification by disseminating into various terminological options, unlike the French space, where the debates and polemics within the field of translation critique proved beneficial for managing the Freudian conceptual system. Already familiarized with a theoretical complex and with some of the author's opinions 
regarding the challenges of translating concepts in humanities discourse, we are presented here with a multivalent analysis. In this analysis, the assessment targets not only the issue of concepts, but also other reference points: lexicon, syntax, style, idioms, "untranslatables", critical apparatus. The downsides identified in the confused project of the Romanian translation are numerous: from the terminological fluctuation that often fails to achieve conceptual unification to contradictory lexical and syntactic loan translations, misplaced sentences, semantic and stylistic incoherence, etc. The main conclusion of the investigation comprised in the last chapter is the need for a solid critical apparatus. Thus, Magda Jeanrenaud highlights the essential role of certain considerations, especially concerning the translation of conceptual terms, in the absence of which the potential confusions, mistranslations or logical contradictions can be imputed by the receiver not to the translator, but to the author of the translated text.

The mere transcoding of the terms from the source language does not guarantee the same effect in the target language, and this aspect justifies the author's confidence in the ethical imperative of translation. Hence, the author concludes, Freud's translator "should first of all (and maybe even last of all) be (simply) a professional translator, but they should also master the subtleties of their own mother tongue" (p. 186). The clear tone of the text does by no means reveal the intention of discouraging a new translation project. On the contrary, it shows the author's attempt of accentuating the need of a new translation of Freud's work into Romanian, through a conscious effort of reflecting on the process per se, cumulated with an open dialogue with the model of other cultures.

In harmony with the opening of this volume, the author ends her endeavour by using three short accounts "with moralizing connotations", focusing on a more active and profound reception of the thematic core of the book (In this respect, the mottos introduced at the beginning of each of the five studies are equally important). The main idea of the ending text is that, despite the difficulty of accepting new translation versions, mostly in contexts where philological principles are in conflict with theological principles or even with affective arguments, the temporal horizon actually justifies the need for a new translation.

We can conclude that the purpose of the entire volume is precisely to challenge the translators, to encourage them to approach certain texts without imposing on themselves the ideal of a perfect endeavour, but by understanding that they will be involved in a continual process, in a perpetually perfectible project. If "it is this mourning for the absolute translation that produces the happiness associated with translating", according to Paul Ricœur (P. Ricœur, On Translation, translated by Eileen Brennan, Routledge, London and New York, 2006, p. 10), maybe it would not be wrong for a translator to seek the same pleasure in the practice of retranslation. Actually, this endeavour is governed by an ethical imperative that sends them constantly to the reference points provided by the critique and evaluation of the previous translations.

The major ideas pertaining to translation theory and critique debated in this volume are not necessarily new, as they represent constants of the theoretical and exegetic complex that Magda Jeanrenaud employs for Romanian translation studies and for general translation studies, implicitly. Such ideas are maybe presented in a more detailed manner in previous works of the author. However, the novelty and the undisputable value of this work are represented precisely by the conjugation of these ideas with the practical exercises mentioned in the title, the purpose of which is to cover a topic that is very important but also highly neglected: the ethics of translation. 